\title{
Energy efficiency management of virtual power plants considering temperature control load \\ Guanlu Yang ${ }^{\mathrm{a}}$, Xiaofeng Chen ${ }^{\mathrm{b}}$, Yajing Lv ${ }^{\mathrm{c}}$ \\ Huaqiao University, Xiamen 361021 ,China \\ aglyang@hqu.edu.cn, b410417815@qq.com, c574189615@qq.com \\ ${ }^{*}$ Xiaofeng Chen
}

Keywords: virtual power plant, demand response, dispatching management, FPGA, GPRS

Abstract. This thesis takes the virtual power plant theory as the research background, designs and builds the dispatch management system based on the virtual power plant. The dissertation completed the software and hardware design of FPGA-based power monitoring device and realized the wireless transmission function based on GPRS network. The dissertation builds a scheduling management system interface based on the virtual power plant theory on the LabVIEW platform, and successfully debugs and completes the production of the power monitoring device on the FPGA system board. The error of the power monitoring device is tested and analyzed, and the experimental verification is based on Feasibility of dispatch management system for virtual power plant.

\section{Introduction}

The virtual power plant is regarded as a special power plant and an integrated energy management system. Through advanced communication technologies and software systems, distributed power sources such as distributed power sources, energy storage devices, and controllable loads are aggregated. Participate in electricity market and power system operation.

At present, foreign researchers mainly focus on the operation mechanism of virtual power plants and their optimization scheduling algorithms. Literature [1] studies the virtual power plants for wind power generation and hydroelectric power generation, and proposes a scheduling method that uses hydroelectric power generation to reduce the prediction error of wind power. Literature [2] established a virtual power plant model including energy storage and demand response. Reference [3] considers controllable and uncontrollable distributed power sources, and proposes a bidding strategy for virtual power plants with the goal of maximizing economic benefits.

China is also actively developing virtual power plant technology, fully mobilizing energy on the demand side and power generation side to promote China's electricity market management system ${ }^{[4]}$. In [5], the optimal economic benefit of virtual power plants is taken as the goal, and an optimal scheduling model considering time-of-use electricity price is established.

The dispatch management system based on virtual power plant designed in this paper is mainly composed of the following parts: dispatch management center, GPRS wireless communication network, energy use monitoring terminal and load resource.The overall structural framework is shown in Figure 1. The energy use monitoring terminal is used to collect the power and status information of the load resource, and transmit the data to the dispatch management center through the GPRS wireless communication network. The dispatch management center stores, analyzes, and processes the data and uploads it to the power dispatching center. The dispatch center issues dispatch instructions according to the relevant information of the load resources, and the dispatch management center implements unified control of load resources. 


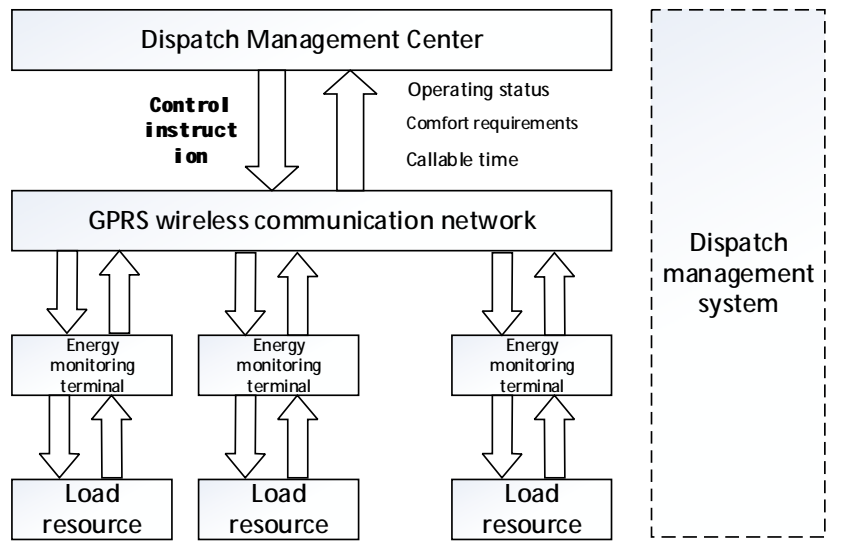

Figure 1 Block diagram of scheduling management system based on virtual power plant

\section{Hardware design of energy monitoring device}

Hardware Design Scheme. The device is mainly composed of transformer module, $A D$ conversion module, FPGA and GPRS module. Among them, the transformer module turns the three-phase voltage and current signals supplied by the power grid into weak signals, and then provides them to the $A D$ conversion module for conversion and processing. FPGA calculates the power parameters of the result of $A D$ conversion, and then outputs the calculated result to the GPRS module through the RS232 interface. Finally, the data is transmitted to the upper computer for display, storage, and processing using the GPRS network. The overall design framework is shown in Figure 2.

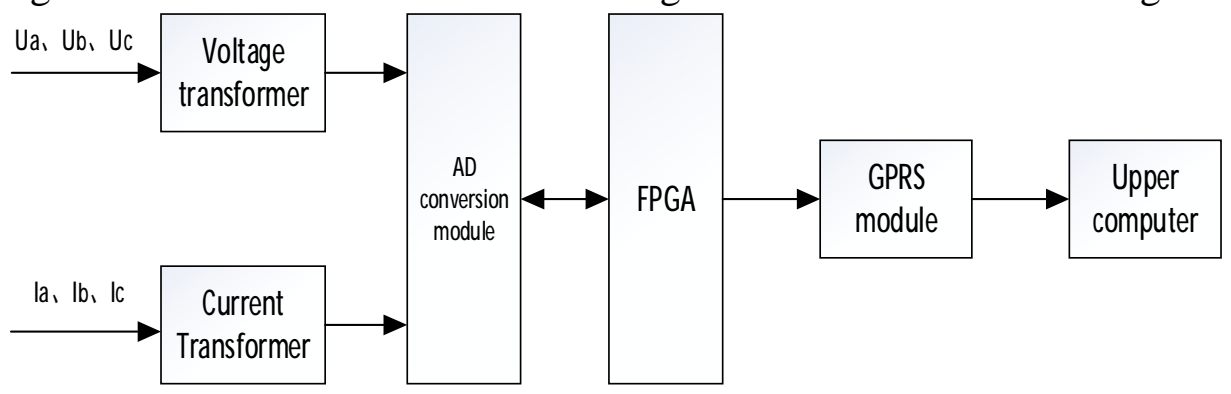

Figure 2 Hardware Design Framework

Transformer Module. The main function of the voltage and current transformers is to convert the three-phase voltage and current signals of the power grid into weak signals to meet the input range of the $A D$ conversion module.The function of the voltage transformer is to convert the strong voltage into a weak voltage for the use of subsequent signal processing devices. The role of current transformer is to convert strong current into weak current signal.

$\boldsymbol{A D}$ conversion module. The system uses a successive approximation $(S A R)$ kernel. It supports $\pm 5 \mathrm{~V} / \pm 10 \mathrm{~V}$ bipolar signal input, single-voltage supply of $5 \mathrm{~V}$ power supply, sampling rate up to $200 \mathrm{kSPS}$, and signal-to-noise ratio $(S N R)$ of up to $95.5 \mathrm{~dB}$ to meet the precision requirements in actual operation.

It can acquire $A D$ converted data through parallel mode or serial mode, and can set the communication mode by setting the PAR/SER/BYTE SEL pin level. This design selects parallel mode to read the $A D 7606 A D$ data. The analog input range of the $A D 7606$ can be set to $\pm 5 \mathrm{~V}$ or $\pm 10 \mathrm{~V}$. This setting can be achieved with the $R A N G E$ pin level.

GPRS wireless communication module. This article uses the industrial grade GPRS DTU wireless communication module to realize the data transmission and load control function of the dispatch management system. Connect the equipment terminal to the GPRS wireless network through the GPRS DTU module, connect the Internet/Ethernet through the gateway, and finally connect with the 
management center, so that the data of the equipment terminal is transmitted to the management center through wireless transmission and sent to the upper computer for implementation. Data display, storage and processing.

\section{Energy monitoring device software design}

The control core of the entire FPGA system is its software part, as shown in Figure 3 is the overall block diagram of the design. The software part of the FPGA mainly implements functions such as zero-crossing detection, frequency detection, $A D$ acquisition, and power parameter calculation. This design adopts Quartus II 13.0 to complete the programming of the on-chip part of FPGA, and use Modelsim to carry out waveform simulation.

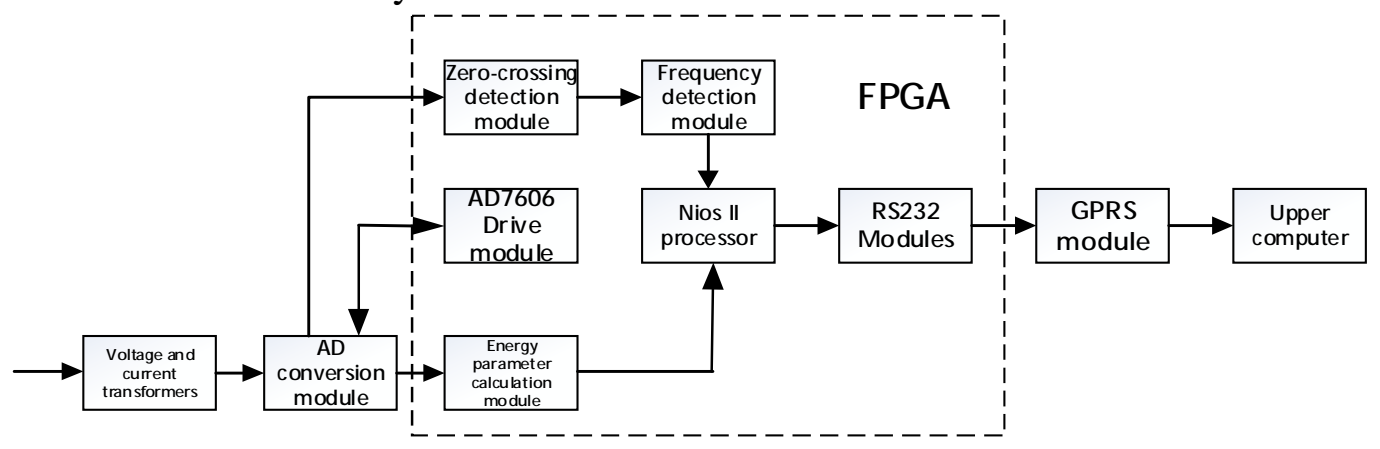

Figure 3 The overall functional block diagram of the FPGA

The frequency detection module detects the output signal of the zero-crossing detection module and uses the periodic measurement method to measure the frequency. This provides the $A D$ chip with an accurate sampling signal with the same spacing. The sampling frequency is kept consistent with the grid frequency, and the protection of each cycle is guaranteed. With the same number of acquisitions (constant $\mathrm{N}$ ), the accuracy of subsequent energy parameter calculations is improved. The design uses 128 points per cycle for acquisition.

\section{Experimental data and verification}

The virtual power plant-based dispatch management system designed in this thesis consists of LabVIEW host computer interface, GPRS network, power and environmental parameters acquisition device, control device and power equipment.The system collects various electrical and environmental information in real time, monitors the real-time energy consumption on the demand side, and then uploads the demand side information to the grid dispatching center through the GPRS network, and implements the demand side load according to the instructions issued by the grid dispatching center. Control and realize remote control of electrical equipment.

Table 1 Some Parameters Error Test of Electrical Energy Monitoring Device

\begin{tabular}{|l|l|l|l|l|}
\hline & Measured & instrument & Absolute error & Relative error \\
\hline A-phase voltage effective value & $224.9(\mathrm{~V})$ & $224.5(\mathrm{~V})$ & 0.4 & $0.18 \%$ \\
\hline A-phase current $R M S$ & $7.15(\mathrm{~A})$ & $7.2(\mathrm{~A})$ & 0.05 & $0.69 \%$ \\
\hline A phase active power & $1.28(\mathrm{KW})$ & $1.3(\mathrm{KW})$ & 0.02 & $1.5 \%$ \\
\hline A-phase power factor & 0.80 & 0.81 & 0.01 & $1.2 \%$ \\
\hline B-phase voltage effective value & $226.0(\mathrm{~V})$ & $225.9(\mathrm{~V})$ & 0.1 & $0.04 \%$ \\
\hline B-phase current $R M S$ & $5.47(\mathrm{~A})$ & $5.5(\mathrm{~A})$ & 0.03 & $0.54 \%$ \\
\hline B phase active power & $0.99(\mathrm{KW})$ & $1.0(\mathrm{KW})$ & 0.01 & $1 \%$ \\
\hline
\end{tabular}




\begin{tabular}{|l|l|l|l|l|}
\hline B-phase power factor & 0.79 & 0.80 & 0.01 & $1.2 \%$ \\
\hline C-phase voltage effective value & $228.1(\mathrm{~V})$ & $227.8(\mathrm{~V})$ & 0.3 & $0.13 \%$ \\
\hline C-phase current $R M S$ & $5.76(\mathrm{~A})$ & $5.8(\mathrm{~A})$ & 0.04 & $0.69 \%$ \\
\hline C phase active power & $0.98(\mathrm{KW})$ & $1.0(\mathrm{KW})$ & 0.02 & $2 \%$ \\
\hline C-phase power factor & 0.70 & 0.72 & 0.02 & $2.8 \%$ \\
\hline frequency & $50.0(\mathrm{~Hz})$ & $50.02(\mathrm{~Hz})$ & 0.02 & $0.04 \%$ \\
\hline
\end{tabular}

Table 1 shows the parameter error test of the power monitoring device of this system.The measurement error of this device can basically be controlled within $1 \%$, can accurately measure the electrical energy information of the electrical equipment, and has passed the inspection of the quality inspection department.

\section{Conclusions}

The concept of a virtual power plant brings together a variety of distributed power sources, controllable loads, and energy storage units as a power plant that can participate in the scheduling and management of the electricity market and grid operations.According to the load operation characteristics of the air conditioner and the water supply system, the hardware and software components of the power monitoring device are designed, so that the device can not only complete the monitoring of the user power consumption by the dispatch management system, but also effectively realize the user side and scheduling through remote wireless transmission. The interaction of the management center; the error of the electric energy monitoring device was tested and analyzed, and the device was able to accurately measure the electric energy information of the electric equipment. The feasibility of the virtual power plant based dispatching management system was verified by experiments.

\section{Acknowledgements}

This work was financially supported by Fujian Province Science and Technology Plan Project (2014H0031).

\section{References}

[1] Praca I, Morais H, Ramos C, et al. Multi-agent electricity market simulation with dynamic strategies \& virtual power producers[C]// Power and Energy Society General Meeting Conversion and Delivery of Electrical Energy in the, Century. IEEE, 2008:1-8.

[2] Pudjianto D, Ramsay C, Strbac G. Virtual power plant and system integration of distributed energy resources[J]. Renewable Power Generation Iet, 2007, 1(1):10-16.

[3] You S, Traeholt C, Poulsen B. A market-based Virtual Power Plant[C]// International Conference on Clean Electrical Power. IEEE, 2009:460-465.

[4] Wei Xiangxiang, Yang Dechang, Ye Bin. The operation mode of the virtual power plant in the energy internet and its inspiration [J]. Power Construction, 2016, 37(4):1-9.

[5] Yuan Guili, Chen Shaoliang, Liu Ying, et al. Time-based price-based power plant economic optimization scheduling [J]. Power Grid Technology, 2016, 40(3): 826-832. 